University of Warwick institutional repository

This paper is made available online in accordance with

publisher policies. Please scroll down to view the document

itself. Please refer to the repository record for this item and our

policy information available from the repository home page for further information.

To see the final version of this paper please visit the publisher's website. Access to the published version may require a subscription.

Author(s): Matthew Watson

Article Title: Searching for the Kuhnian moment: the Black-ScholesMerton formula and the evolution of modern finance theory

Year of publication: 2007

Link to published version:

http://dx.doi.org/10.1080/03085140701254340

Publisher statement: None 
Searching for the Kuhnian Moment:

The Black-Scholes-Merton Formula and the Evolution

of Modern Finance Theory

\author{
Matthew Watson \\ Department of Politics and International Studies \\ University of Warwick
}

Published in Economy and Society, 36 (2), 2007, 326-338. 


\title{
Searching for the Kuhnian Moment: \\ The Black-Scholes-Merton Formula and the Evolution \\ of Modern Finance Theory
}

Perry Mehrling, Fischer Black and the Revolutionary Idea of Finance, Hoboken, NJ: John Wiley and Sons, 2005.

Donald MacKenzie, An Engine, Not a Camera: How Financial Models Shape Markets, Cambridge, MA: MIT Press, 2006.

\begin{abstract}
The Black-Scholes-Merton formula has been put to widespread use by options traders because it provides a means of calculating the theoretically 'correct' price of stock options. Traders can therefore see whether the market price of stock options undervalues or overvalues them compared with their hypothetical Black-ScholesMerton price, before choosing to buy or sell options accordingly. As a consequence of this close relationship between options pricing theory and options pricing practice, a strong performativity loop was activated, whereby market prices quickly converged on the hypothetical Black-Scholes-Merton prices following the dissemination of the formula. The theory has therefore had significant real-world effects, but how should we characterise the initial instinct to derive the theory from a philosophy of science perspective? The two books under review suggest that a Kuhnian reading of the advancement of scientific knowledge might well be the most appropriate. But, on closer inspection it becomes clear that the publication of the Black-Scholes-Merton formula should not be seen as a Kuhnian moment with paradigm-shaping attributes. It is shown that, at most, the formula acts as an important exemplar which, via its use in the training of options pricing theorists and options pricing practitioners, reinforces the entrenchment of finance theory within the orthodox economics worldview.
\end{abstract}

\section{Key Words}

Black-Scholes-Merton formula; options pricing theory; Kuhnian science; paradigms; exemplars. 
It is often said by those whose work focuses on the constitutive and causal effects of ideas that their aim is to correct the tendency for ideas to be taken insufficiently seriously. The same charge most emphatically cannot be levelled against these two excellently researched, articulately written and provocatively argued books. The genealogy of financial economists' treatment of one idea in particular is central to both books: the idea that a mathematically tractable 'ideal' price exists for exchangetraded options, such that an increasingly rigorous and scientific basis for hedging and arbitrage practices can be institutionalised across a range of different financial markets. It is this idea which resulted in the celebrated Black-Scholes-Merton formula for solving the options pricing problem.

Both books follow Peter Bernstein’s pioneering lead (1992) in explaining the initial intuition underpinning options pricing theory within the history of the evolving ideas which revolutionised academic finance in the mid to late twentieth century. Perhaps the biggest compliment to be paid in this respect is that both bear direct comparison to Bernstein's seminal contribution in terms of the depth of the analysis and the insights they provide. The emphasis differs in each case, however, from Bernstein's attempt to write a general history of modern finance theory. On the one hand, Perry Mehrling weaves the intellectual biography of arguably the most influential of all modern finance theorists, Fischer Black, into Bernstein's history of the field as a whole. On the other hand, Donald MacKenzie focuses more on the way in which the academic ideas became embedded via a performative loop in the day-today operation of financial markets.

Yet, it would be a mistake to concentrate solely on these differences, because the underlying theme of both books is remarkably similar. That is to emphasise the practical effects of modern finance theory and, in general, those effects divide in two. 
First, the guiding intuition of the Black-Scholes-Merton formula has been turned into a largely unquestioned framework of thinking for subsequent generations of finance theorists. It is no exaggeration to say that the solution to the options pricing problem has been accepted as the professionalised common-sense of financial economics (e.g., Jensen 1978: 95). Second, the guiding intuition of the Black-Scholes-Merton formula is now fully embedded in the trading strategies on which market participants rely in order to keep their businesses afloat. The solution to the options pricing problem has also been accepted, pretty much across the board, as the starting point for practitioner activity within the market environment (e.g., Derman 2004: 5-8). No greater demonstration that ideas matter could arguably be forthcoming than to be able to show that a single solution to a single hypothetical problem has so thoroughly penetrated the activities of two such diverse communities as market theorists and market traders.

My point of departure in this review is not to question either the fact or the extent of these effects. Mehrling and MacKenzie make such compelling cases about their existence, built on in-depth interview evidence from the relevant communities, that I am fully persuaded. Instead, I intend to ask how best we might conceptualise such effects. In particular, are there traditions in the philosophy of science literature which help us to explain how a single idea can displace all previous ways of thinking about a problem and become the one accepted intellectual framework for all future analyses of that problem?

There are enough hints in the underlying commentary of both books to suggest that the most appropriate place to begin this investigation is Thomas Kuhn's classic study, The Structure of Scientific Revolutions (Kuhn 1970). Even the title of Mehrling's book highlights the potentially revolutionary nature of the Black-Scholes- 
Merton formula which solved the options pricing problem. Moreover, the notion of a revolution is invoked in a directly analogous manner to Kuhn's specific usage (ibid: 92-110), suggesting that the professional instincts of financial economists were completely overhauled, never to be the same again (e.g., pp. 10, 14). MacKenzie is more explicit. He suggests that the fundamental shift which has occurred in modern finance theory is most assuredly Kuhnian in both its content and its outcomes. The unveiling of the Black-Scholes-Merton formula is presented as “a Kuhnian moment” (p. 139), whilst the options pricing problem which elicited the formula is described as “a tantalizingly straightforward 'normal science' problem, in the terminology of Kuhn” (p. 31).

Before this characterisation can definitely be adopted, though, it is necessary to inquire further about how Kuhn's precise meaning of 'scientific revolution’ relates to his better known concept of paradigmatic thought, and whether his understanding of knowledge formation in general can be transposed from the natural science frameworks in which it was first developed to modern finance theory. As the review unfolds, it will become clear that I am tempted to go part way towards accepting the Kuhnian characterisation of modern finance theory, but I am also inclined to stop short of fully endorsing it, especially in terms of relating the origins of modern finance theory’s Kuhnian character specifically to the Black-Scholes-Merton theorem.

\section{Paradigms and Modern Finance Theory}

Kuhn's notion of a paradigm undergoes significant reformulation between his earlier and his later work. In its original form, it is a radical challenge to presumptions about 
scientific rationalism (Anderson, Hughes and Sharrock 1986: 251). Kuhnian science is depicted as an inherently conservative social institution, in which to be treated as a legitimate entrant into debates is to accept, largely unreflexively, the existing norms of the scientific community (Musgrave 1980: 41-2). Under pressure from his critics, though, Kuhn subsequently backed away from this depiction, concerned that his notion of a paradigm invited confusion, due to his propensity to use it to describe shifts in the orderly way of thinking of very different scale and impact (Newton-Smith 1981: 103-4). Kuhn accepted (1977: 294-5) that his original use of the concept had been overly liberal, and he latterly restricted it to just two senses.

1. One was an attempt to preserve the general meaning he was trying to capture in his original thesis: this was the uniform effects on cognition which arise in the context of socially bounded scientific communities that are controlled through the exercise of patronage (Eckberg and Hill 1980: 117-8). Kuhn came to call this a 'disciplinary matrix' (1970: 182-5), emphasising that this usage referred to the regulated constellation of beliefs which a scientific community holds about the appropriate way of doing science.

2. The other represented a new attempt to focus attention on the pedagogical strategies which are deployed in order to filter scientific common-sense down from one generation of scientists to another. Kuhn came to call this inculcation of learned intuitions exposure to ‘exemplars’ (1977: 297-8). He emphasised the way in which textbook learning by rote had replaced genuine reflection as the means through which trainee scientists develop professionalised habits of thought (Barnes 1982: 17-8; Margolis 1993: 7). 
There are consequently two dimensions to paradigms: one intellectual and the other institutional (Hollis 1994: 85-6). Moreover, Kuhn is clear about how they come together in his assertion that (1970: 180): “A paradigm governs, in the first instance, not a subject matter but rather a group of practitioners”. Paradigmatic thought thus does nothing to alter what of interest might be seen in the world, but it does affect what those who are trained to speak authoritatively about the world will be of a mind to look for in it. Accordingly, paradigms are socially regulated consensus-building platforms which provide scientists with the practical instincts to guide their day-today operations (Bird 2000: 67-8). The paradigm shifts associated with scientific revolutions therefore eradicate one expression of systematised common-sense and replace it with another. To allow oneself to become acculturated to the learned intuitions of a rival paradigm requires the "adoption of a somewhat different 'rationality' at the metalevel” (McMullin 1993: 65). Given the leap of faith involved in such a shift, Kuhn is adamant (1970: 206) that the historical progression of knowledge is governed by something other than a "coherent direction of ontological development”. One disciplinary matrix might therefore replace another, but this will be for reasons relating to the social control of scientific communities rather than to some supposedly objective standards of science.

So, how closely do the changes in finance theory documented in the books under review correspond to Kuhn's reworked conception of a paradigm shift? A paradigm shift becomes fully institutionalised at the point at which the exemplars which supported the previous disciplinary matrix are replaced. However, as the initial shift takes place at the level of the disciplinary matrix, I focus on this aspect for now, whilst leaving for later the discussion of the exemplars which sustain modern finance 
theory as a professionalised scientific pursuit. Four points might usefully be made in this regard about the disciplinary matrix of modern finance theory.

1. Allowing for Wes Sharrock and Rupert Read's well-made observation that Kuhnian historians of science tend to replay the gestalt switch of paradigmatic change more quickly than it occurred in real time (2002: 177), the systematic shift in both the procedural and the content basis of finance theory is very much as Kuhn attributes to paradigmatic thought. Prior to Harry Markowitz’s seminal work on portfolio selection in the 1950s (e.g., 1959), the starting point for finance theory had generally been the firm and its decisions of how best to raise the money to fund its business operations. Fund managers had previously incorporated discounted cash flow techniques into their analysis of possible investment decisions, but this made very little impact on academic theories of finance, which still tended to emphasise the firm. Markowitz's approach was very different. He asked instead how individual investors should seek to balance their stock portfolios in order to maximise their potential returns at any given level of risk. From that point on, all notable advances in finance theory have concentrated on hypothetical issues relating to 'the market' and not practical issues relating to financing the firm (e.g., Mehrling, pp. 10, 225-6; MacKenzie, pp. 73-4, 244). Amongst its practitioners, the constellation of beliefs about what it means to be doing financial economics is now firmly fixed on this market-based approach to the subject matter. In this way, there is a clear parallel with what Kuhn had in mind by the imposition of a new 'disciplinary matrix'. 
2. Set directly against this, though, it is unclear whether the development of modern finance theory actually represents a new disciplinary matrix or merely the transposition of the subject matter of financial economics from one discipline to another. Kuhn is adamant (1970: 180) that a paradigm regulates the practitioners of science and not the subject matter on which they work. But this image is not necessarily easy to reconcile with developments in finance theory. The watershed moment should once again be seen as Markowitz's work on portfolio selection, because this represents the first time that the theories, methods and basic intuitions of economics had been applied to finance theory in any systematic manner. So new was this approach that Milton Friedman, one of Markowitz's examiners, was initially reluctant to award Markowitz his economics PhD: not on the grounds of the quality of the thesis, but on whether the subject matter was actually economics (Bernstein 1992: 60). From Markowitz onwards, what might be seen as a scientific revolution in finance theory could also be merely the increasingly pervasive encroachment of economists into the subject field of financial markets and their eventual displacement of the business school theorists who had once had that field to themselves. MacKenzie (p. 67), for instance, writes that, by the late 1960s: “The financial markets had been captured for economics” (see also Mehrling, p. 128). No such dynamic of capture is evident in Kuhn's description of paradigm change and, for this reason, his concept of a disciplinary matrix must be applied with caution to modern finance theory. In order to say that a new disciplinary matrix has been created, we would have to be able to prove the counterfactual that economists would not have applied their standard model of maximising behaviour to financial markets had they 
shown more interest in the subject matter in the pre-Markowitz era. This seems unlikely; moreover, it is, of course, an untestable proposition.

3. If we suspend our caution on this point for one moment, then we can find another element in the evolution of finance theory which fits the notion of a disciplinary matrix much more satisfactorily. As soon as economists began to show a professional interest in financial markets, the development of finance theory "has something of the character of a cascade" (MacKenzie, p. 243). Markowitz’s work was refined further and turned into a fully specified model - the Capital Asset Pricing Model (CAPM) - by his doctoral student, William Sharpe. Sharpe's model (e.g., 1970) then became the object of attention for the next generation of Chicago-based finance scholars, who tried to find a way of solving it in mathematically tractable form. Both Fischer Black and Myron Scholes passed through Chicago en route to MIT and the beginning of the collaboration which would result in the solution to the options pricing problem. Also at MIT at that time, Paul Samuelson was developing an alternative economic approach to financial markets, and it was his doctoral student, Robert Merton, who was able to demonstrate that the Black-Scholes solution was mathematically robust. Scholes and Merton were then prominent in supervising the succeeding generation of students who refined finance theory still further. Significantly, as Sharpe, Scholes and Merton had done before them, these students also took their supervisors’ starting assumptions along with the learned intuitions which allowed those assumptions to make sense - as a given. More so than any of the other social sciences, economics mirrors the natural sciences in the patronage that determines the choice of 
what to study for young scholars (Eichner 1983: 227-8). PhD topics are given to students by their supervisors and, in this way, supervisors' habits of thought are passed down, often unknowingly, in the process of learning how to be accepted amongst the community of economists.

4. However, another word of caution has to be issued in this respect. It appears to be appropriate to think in terms of a disciplinary matrix when discussing the structure of modern finance theory. Yet, according to Kuhn (1977: 297-9), disciplinary matrices are forged in a moment of scientific revolution and rely for their coherence on a single path-breaking intervention. It is unclear, though, exactly what the foundational intervention is in the creation of the disciplinary matrix of modern finance theory. With his specific focus on the life and work of Fischer Black, it is easy to assume for Mehrling that the answer is the Black-Scholes-Merton solution to the options pricing problem. Moreover, when MacKenzie’s 'cascade' of advances in finance theory was at its height in the late 1970s, doctoral students learned what financial economics was specifically through being trained in the economic intuitions of Black and Scholes (1973) and Merton (1973). But MacKenzie also describes this work, in Kuhnian terms, as being part of a 'normal science' tradition (p. 31). At most, then, training through the Black-Scholes-Merton formula enhances the process of consensus-consolidation within the community of financial economists, rather than being responsible for consensus-creation in the first place. Its publication is not the moment of scientific revolution which establishes a paradigm, so much as the model which enables paradigmatic thought to be increasingly inculcated as professional common-sense. So, 
where might the paradigm-establishing moment of scientific revolution be located? For Mehrling, it is clearly with Sharpe's CAPM, because this is what had the greatest effect on Black. A wonderfully evocative picture is painted of Black as the human embodiment of the CAPM, such was his desire to construct not only his academic way of thinking but also his general way of living on its insights (pp. 130-1, 138). Yet, MacKenzie shows that Merton consciously rejected the CAPM in his approach to the options pricing problem, believing it to be some combination of theoretically old-hat and empirically wrong (pp. 134-6). In Merton's hands, then, Sharpe’s CAPM had just as restricted a shelf-life as Markowitz’s portfolio selection theory, which was also very quickly displaced as the starting point for financial economics (Bernstein 1992: 201). As a consequence, the jury must still be out as to whether modern finance theory has an instant of scientific revolution and, if it does, in which publication that instant is to be found. This is a poor fit with Kuhn's notion of paradigmatic thought.

The evidence for whether modern finance theory approximates a Kuhnian paradigm can therefore be read both ways. However, up to this point I have concentrated exclusively on the 'disciplinary matrix' understanding of a paradigm. It is now necessary to turn to the rival 'exemplar' understanding, to ask whether the BlackScholes-Merton formula is of particular importance in this regard. 


\section{The Black-Scholes-Merton Theorem as Performative Exemplar}

In seeking to illustrate the pedagogical power of exemplars, Kuhn emphasises the difference between how the world might look to us in pure observational terms and how it looks in theoretical terms (1970: 119-26). Given that a process of translation must always intervene in order to impose meaning on observations, it is the theoretical view of the world which is more important (Musgrave 1980: 47). As Sharrock and Read argue in explaining Kuhn’s position (2002: 178): “Our knowledge of the world ... must always involve two elements: a contribution from the world, and a contribution from our minds, with the latter (so to speak) endowing structure upon the former”. The suggestion, then, is of a radical and incommensurable split between the 'external world' of nature and a plurality of potential 'phenomenal worlds' which scientific practices first construct and then inhabit. Particular practices come to predominate, not because they offer privileged access to understanding the external world, but because they are explicable in their own terms from within the paradigmatic thought processes associated with the prevailing phenomenal world (Shapere 1980: 29; Hacking 1983: 185).

As a consequence, the only thing which presents itself for empirical investigation is the phenomenal world created by the central tenets of scientific orthodoxy; the external world cannot be apprehended in this way (Hoyningen-Huene 1993: 34-5). Even then, the phenomenal world is not interrogated as an authentic representation of what it might be were it actually the external world. Rather, all understandings of its structure and its content are mediated by scientists’ familiarity with standard exemplars, constant interaction with which helps them to visualise the phenomenal world in a particular way. This means that, from a Kuhnian perspective, 
science is not a matter of comparing theories with nature, so much as comparing theories with their own conception of how nature should perform, where that conception is learned directly through exposure to exemplars.

This is where an important distinction must be drawn between Kuhn's conception of science and the world in which modern finance theorists have worked. For Kuhn, scientists operate within their own internal phenomenal worlds, and the acculturation to a new set of theories only involves a shift between different phenomenal worlds. In turn, this is about changing the interpretation of natural phenomena, not changing nature itself. A different process is implied in the shift between different finance theories. An increasing number of scholars - Mehrling (pp. 9-14) and MacKenzie (pp. 12-20) amongst them - have pointed to the capacity for economic theory to have performative effects on actual economic relations (e.g., Miller 1998: 195-9; Breslau 2003: 384-5; Ferraro, Pfeffer and Sutton 2005: 13-4). In other words, incorporating the implications of economic theory into economic practice creates an economy which increasingly comes to resemble the relationships inferred by the theory.

This is where the significance of the Black-Scholes-Merton theorem is really revealed. For, the strongest evidence of performativity in modern finance theory involves the theorem and its use as an exemplar for training interested parties in the art of calculating the 'true value' of an options contract. Treating the theorem as the key exemplar which unlocks the phenomenal world of modern finance enables traders to work out whether the prevailing market price of an option means that it is currently overvalued or undervalued. It does so by providing unique insights into the ‘equilibrium' price which equates to a smoothly functioning and distortion-free market. Strong performativity was signalled by the speed with which market prices 
converged on the Black-Scholes-Merton price (Mehrling, pp. 139, 249; MacKenzie, pp. 32, 37-8, 166).

The first fully-fledged exchange for trading options on financial assets was only established in April 1973. At that time, traders were unused to constructing deals containing options on financial instruments, so they based their decisions on ad hoc trading rules derived from specialist trading in other markets. Later in 1973, though, the academic journal articles which underpinned the Black-Scholes-Merton theorem appeared (Black and Scholes 1973; Merton 1973). These articles provided a formal specification of a mathematically tractable guide to equilibrium options pricing and, as such, they served as the basis for an easily understandable trading rule. The result was that the theorem came to be readily incorporated into the institutional fabric of financial options markets. In the stock options market, for example, the average market price premium fell from around a 30\% mark-up on the equilibrium BlackScholes-Merton price when exchange-traded options first became available in 1973 to an astonishingly small mark-up of 2\% in 1978 and then again to a mark-up of only 1\% immediately before the destabilising shock of the 1987 stock market crash (Rubinstein 1994: 774; MacKenzie, pp. 158-77). This shows that traders were willing to base their investment decisions, not on the grounds of any great intuition about how the world actually works, but on the grounds of how options pricing theory said it should work. In the process, traders' activities served to confirm in practice the insights of options pricing theory.

This outcome was all the more noteworthy given that, at the time of its initial publication, it was impossible to enter the world of the Black-Scholes-Merton theorem in order to act upon its implications. The theorem relates merely to one of Kuhn's phenomenal worlds, but the multiple restrictions on trading activities designed 
to protect investors from exposure to a pure market mentality meant that the world which options traders actually inhabited was markedly different. Equilibrium only arises in the theorem's phenomenal world when no arbitrage opportunities remain and consequently prices are stable (Derman 2004: 6-8). The Black-Scholes-Merton theorem therefore had the potential for strong performativity right from its inception, because the central mechanism in the phenomenal world, arbitrage, is also the central component of trading practice. However, the practicalities of market trading did not initially match the potential for performativity. Financial options arbitrage initially took place within tightly circumscribed moral, legal and institutional limits, due to residual fears expressed by policy-makers that trading in financial futures was a sophisticated form of gambling rather than an act of real economic worth (de Goede 2004: 201). Very quickly, though, the performative potential of the theorem was released. Its promise to reduce investors’ risk exposures was particularly important in softening regulators' reluctance to endorse options trading which conformed to pure market principles. Following a whole series of regulatory relaxations, the world inhabited by options traders increasingly came to resemble the phenomenal world of the Black-Scholes-Merton theorem.

But let us backtrack for a moment, to focus once again on the origins of the formula which solved the options pricing problem. The basic argument underscoring the Black-Scholes-Merton theorem had been given many outings at academic seminars before it was physically possible to deal in exchange-traded options in financial instruments (Bernstein 1992: 220-2). In its original form, then, the theorem was little more than a thought experiment. However, this makes it no less significant. Indeed, in his later work, Kuhn asks whether the ability to facilitate highly consequential thought experiments was potentially the most important feature of a 
paradigm. At the very least, a well-constructed thought experiment provides an internal check on how robust a paradigm's major arguments are.

Kuhn is insistent (1981: 7, emphases in original) that "the new understanding produced by thought experiments is not an understanding of nature but rather of the scientist's conceptual apparatus". Thought experiments can only be tested in the first instance as a matter of logic, and it is the prevailing paradigm which imparts analytical meaning onto the logical sequences which thought experiments highlight. Thought experiments therefore take place within the context of an existing paradigm; they have an affirmatory intent in relation to the internal structure of the paradigm rather than possessing paradigm-creating features of their own. In Kuhn's words (ibid: 14), they are "a propaedeutic to the full discussion". This means that they act in a preparatory sense to facilitate understanding of the introductory premises of a science, as opposed to being constitutive of science in their own right. From this perspective, the initial derivation of the Black-Scholes-Merton theorem, its easy acceptance as the common-sense of both academic theorists and market practitioners and the strong performativity of its application are all evidence of its commensurability with existing paradigmatic thought in the field of economics.

The theorem today is used as such a key exemplar for finance theory that it provides significant impetus for the reproduction of the disciplinary matrix within which financial economists work. But this tells us only about the evolution of its status from its original role as a thought experiment. In that initial form, the BlackScholes-Merton theorem was merely a means of testing whether the prevailing disciplinary matrix of financial economics was robust. The outcomes of the test had a curious effect insofar as they were able to become increasingly true over time due to the performativity loop the theorem initiated via its incorporation into trading 
strategies. Yet, it was only the fact that the test proved positive in the first place which allowed the theorem to subsequently become such a significant exemplar for training new generations of financial economists into the habits of thought of the prevailing disciplinary matrix. It was not an exemplar in its original form, as the institutional capacity was simply not present at the time of its initial publication for it to act in that capacity. It only latterly acquired the potential to be used as an exemplar.

\section{Conclusion}

To sum up, this brings me back to the main question underpinning the review. There is ample evidence of Kuhnian themes in the intellectual history of modern finance theory, as the work of Mehrling and MacKenzie readily demonstrates. However, is there a definitive Kuhnian moment giving both clarity and direction to this process? Given that the Black-Scholes-Merton theorem has had more practical effects on investor behaviour than any other aspect of modern finance theory, it is understandable that Mehrling and MacKenzie focus so much of their search for an answer to that question on the theorem's origins. But its clear status originally as a thought experiment suggests that, if we are to apply Kuhn's framework in as authentic a manner as possible, then it can be no more than what he calls 'a propaedeutic to the full discussion'. So, if the Black-Scholes-Merton theorem is merely a propaedeutic the question remains as to what, exactly, constitutes the full discussion?

To answer this, it may well be necessary to conclude that the most important factors determining the practice of modern finance theory are not to be found in the 
realm of finance theory itself. The most distinctive feature of that theory is that it no longer constitutes an autonomous body of work in its own right. The standard procedure of finance theory is now to conceptualise every analytical problem as if the only practical task was to devise market institutions for coordinating behaviour in line with the allocatively efficient solution. As such, finance theory today explores the logical properties of equilibrium behaviour in the buying and selling of financial instruments and, in this respect, it is indistinguishable from any other branch of economics in terms of its underlying methodology. The dramatic shift in finance theory in the second half of the twentieth century, so ably documented by Mehrling and MacKenzie, at heart was a shift in what it meant to be a finance theorist. It is the story of the encroachment of economists into a previously alien subject field and their speedy appropriation of it. Thus, the search for a Kuhnian moment in modern finance theory involves explaining the increasing colonisation of other research traditions by the economics worldview.

In and of itself, the Black-Scholes-Merton theorem was neither constitutive of the disciplinary matrix which guides the intuitions of modern finance theorists nor was it the original exemplar which confirmed the shift in finance theory in line with the economics worldview. It therefore had nothing to do with whatever organic Kuhnian moment historians of finance theory subsequently want to read back in to its modern-day practices. Yet, the Black-Scholes-Merton theorem has still had Kuhnian effects, even if it is to enforce a misplaced chronology onto modern finance theory to talk about it initiating a paradigm shift in academic approaches to financial questions. It was without doubt the most important thought experiment assisting the process of institutionalising the new habits of thought which persist up to this day in finance theory. Indeed, so successful was it in demonstrating that the economics worldview 
provides a robust logical basis for finance theory that it now acts as the key exemplar securing the reproduction of the new disciplinary matrix. Despite its significance in this respect, though, the Kuhnian chronology must still appear in the correct order: the paradigm shift in finance theory came first, and the development of the BlackScholes-Merton theorem followed as a reflection of the move to a new disciplinary matrix, not the other way around.

\section{References}

Anderson, R.J., Hughes, John and Sharrodk, W.W. (1986) Philosophy and the Human Sciences, London: Routledge.

Barnes, Barry (1982) T.S. Kuhn and Social Science, London: Macmillan.

Bernstein, Peter (1992) Capital Ideas: The Improbable Origins of Modern Wall Street, Hoboken, NJ: John Wiley and Sons.

Bird, Alexander (2000) Thomas Kuhn, Chesham: Acumen.

Black, Fischer and Scholes, Myron (1973) 'The Pricing of Options and Corporate Liabilities’, Journal of Political Economy 81 (3): 637-654.

Breslau, Daniel (2003) 'Economics Invents the Economy: Mathematics, Statistics, and Models in the Work of Irving Fisher and Wesley Mitchell', Theory and Society 32 (3): 379-411.

de Goede, Marieke (2004) 'Repoliticizing Financial Risk’, Economy and Society 33 (2): 197-217.

Derman, Emanuel (2004) My Life as a Quant: Reflections on Physics and Finance, London: John Wiley and Sons. 
Eckberg, Douglas Lee and Hill, Lester (1980) 'The Paradigm Concept and Sociology: A Critical Review', in Gary Gutting (ed.) Paradigms and Revolutions: Appraisals and Applications of Thomas Kuhn's Philosophy of Science, London: University of Notre Dame Press, pp. 117-136.

Eichner, Alfred (1983) 'Why Economics is Not Yet a Science', in idem (ed.) Why Economics is Not Yet a Science, London: Macmillan, pp. 205-241.

Ferraro, Fabrizio, Pfeffer, Jeffrey and Sutton, Robert (2005) 'Economics Language and Assumptions: How Theories Can Become Self-Fulfilling', Academy of Management Review30 (1): 8-24.

Hacking, Ian (1983) Representing and Intervening: Introductory Topics in the Philosophy of Natural Science, Cambridge: Cambridge University Press.

Hollis, Martin (1994) The Philosophy of Social Science: An Introduction, Cambridge: Cambridge University Press.

Hoyningen-Huene, Paul (1993) Reconstructing Scientific Revolutions: Thomas S. Kuhn's Philosophy of Science, translated by Alexander Levine, Chicago: University of Chicago Press.

Jensen, Michael (1978) 'Some Anomalous Evidence Regarding Market Efficiency’, Journal of Financial Economics 6 (2/3): 95-101.

Kuhn, Thomas (1970) The Structure of Scientific Revolutions, second edition, Chicago: University of Chicago Press.

(1977) 'Second Thoughts on Paradigms', in idem The Essential

Tension: Selected Studies in Scientific Tradition and Change, Chicago: University of Chicago Press, pp. 293-319.

(1981) 'A Function for Thought Experiments', in Ian Hacking (ed.)

Scientific Revolutions, Oxford: Oxford University Press, pp. 6-27. 
Margolis, Howard (1993) Paradigms and Barriers: How Habits of Mind Govern Scientific Beliefs, Chicago: University of Chicago Press.

Markowitz, Harry (1959) Portfolio Selection: Efficient Diversification of Investments, London: John Wiley and Sons.

McMullin, Ernan (1993) 'Rationality and Paradigm Change in Science', in Paul Horwich (ed.) World Changes: Thomas Kuhn and the Nature of Science, Cambridge, MA: MIT Press, pp. 55-78.

Merton, Robert (1973) 'Theory of Rational Option Pricing', Bell Journal of Economics and Management Science 4 (1): 141-183.

Miller, Daniel (1998) 'Conclusion: A Theory of Virtualism', in James Carrier and Daniel Miller (eds) Virtualism: A New Political Economy, Oxford: Berg, pp. 187215.

Musgrave, Alan (1980) ‘Kuhn’s Second Thoughts’, in Gary Gutting (ed.) Paradigms and Revolutions: Appraisals and Applications of Thomas Kuhn's Philosophy of Science, London: University of Notre Dame Press, pp. 39-53.

Newton-Smith, W.H. (1981) 'T.S. Kuhn: From Revolutionary to Social Democrat', in idem The Rationality of Science, London: Routledge and Kegan Paul, pp. 102124.

Rubinstein, Mark (1994) 'Implied Binomial Trees’, Journal of Finance 49 (3): 771818.

Shapere, Dudley (1980) 'The Structure of Scientific Revolutions’, in Gary Gutting (ed.) Paradigms and Revolutions: Appraisals and Applications of Thomas Kuhn's Philosophy of Science, London: University of Notre Dame Press, pp. 2738. 
Sharpe, William (1970) Portfolio Theory and Capital Markets, New York: McGraw-Hill.

Sharrock, Wes and Read, Rupert (2002) Kuhn: Philosopher of Scientific Revolution, Cambridge: Polity. 